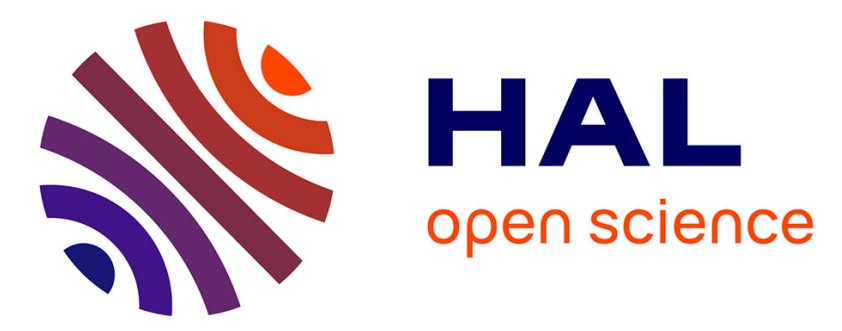

\title{
The three steps of the carbonate biogenic dissolution process by microborers in coral reefs (New Caledonia)
}

\author{
Julie Suzanne Grange, Hervé Rybarczyk, Aline Tribollet
}

\section{To cite this version:}

Julie Suzanne Grange, Hervé Rybarczyk, Aline Tribollet. The three steps of the carbonate biogenic dissolution process by microborers in coral reefs (New Caledonia). Environmental Science and Pollution Research, 2015, Microbial Ecology of the Continental and Coastal Environments, 22 (18), pp.13625-13637. 10.1007/s11356-014-4069-z . hal-01107579

\section{HAL Id: hal-01107579 \\ https://hal.science/hal-01107579}

Submitted on 21 Jan 2015

HAL is a multi-disciplinary open access archive for the deposit and dissemination of scientific research documents, whether they are published or not. The documents may come from teaching and research institutions in France or abroad, or from public or private research centers.
L'archive ouverte pluridisciplinaire HAL, est destinée au dépôt et à la diffusion de documents scientifiques de niveau recherche, publiés ou non, émanant des établissements d'enseignement et de recherche français ou étrangers, des laboratoires publics ou privés. 
1 The three steps of the carbonate biogenic dissolution process by microborers in coral reefs

(New Caledonia)

3

Phone numbers: +33 148027915

julie.grange@locean-ipsl.upmc.fr

\section{Abstract} 0

Grange, J.S. 1; Rybarczyk H. 2; Tribollet A. 1

1: IRD-Sorbonne Universités (Univ. Paris 6) UPMC-CNRS-MNHN, Laboratoire IPSL-LOCEAN, 32 Avenue Henri Varagnat, 93143 Bondy, Fr. 2 : MNHN-Sorbonne Universités (Univ. Paris 6) UPMC-CNRS-IRD, Laboratoire BOREA, 61 rue Buffon, 75005 Paris, Fr

Keywords Microbioerosion dynamics; biogenic dissolution of calcium carbonate; euendoliths; succession of microboring communities; coral reefs; New Caledonia

Biogenic dissolution of carbonates by microborers is one of the main destructive forces in coral reefs and is predicted to be enhanced by eutrophication and ocean acidification by 2100 . The chlorophyte Ostreobium sp., the main agent of this process, has been reported to be one of the most responsive of all microboring species to those environmental factors. However, very little is known about its recruitment, how it develops over successions of microboring communities and how that influences rates of biogenic dissolution. Thus, an experiment with dead coral blocks exposed to colonization by microborers was carried out on a reef in New Caledonia over a year period. Each month, a few blocks were collected to study microboring communities and the associated rates of biogenic dissolution. Our results showed a drastic shift in community species composition between the $4^{\text {th }}$ and $5^{\text {th }}$ months of exposure, i.e. pioneer communities dominated by large chlorophytes such as Phaeophila sp. were replaced by mature communities dominated by Ostreobium sp.. Prior the $4^{\text {th }}$ month of exposure, large chlorophytes were responsible of low rates of biogenic dissolution while during the community shift, rates increased exponentially (x10). After 6 months of exposure, rates slowed down and reached a 'plateau' with a mean of $0.93 \mathrm{~kg}$ of $\mathrm{CaCO}_{3}$ dissolved per $\mathrm{m}^{2}$ of reef after 12 months of exposure. Here we show that (a) Ostreobium sp. settled down in new dead substrates as soon as the $3^{\text {rd }}$ month of exposure but dominated communities only after 5 months of exposure, and (b) microbioerosion dynamics comprise 3 distinct steps which fully depend on community development stage and grazing pressure. 
Coral reefs are highly diverse and complex marine ecosystems, providing many services including commercial fishing, tourism and coastal protection against storms (Knowlton et al. 2010). Their maintenance results from the delicate balance between constructive forces, mainly calcification of corals and encrusting coralline algae, and destructive forces, mostly bioerosion processes (Scoffin et al. 1980, Tribollet \& Golubic 2011). Unfortunately, this equilibrium is increasingly threatened by anthropogenic and environmental factors such as eutrophication, overfishing, rising sea surface temperature and ocean acidification (Hoegh-Guldberg et al. 2007, Pandolfi et al. 2011, Huand 2012). To date, $20 \%$ of coral reefs have already disappeared and $20 \%$ show signs of imminent extinction (Wilkinson 2008). Although both constructive and destructive forces are affected by anthropogenic and climatic stresses (Anthony et al. 2008, Tribollet et al. 2009, Chauvin et al. 2011, Carreiro-Silva et al. 2012, Andersson \& Gledhill 2013, Jessen et al. 2014, Wisshak et al. 2014), much less attention has been given to bioerosion than reef accretion.

Reef bioerosion results from the mechanical and/or chemical activity of living organisms (Neumann 1966) comprising grazers (e.g. urchins and parrotfishes), macroborers (e.g. bivalves and sponges) and microborers or euendoliths (cyanobacteria, algae and fungi) (Glynn 1997, Tribollet \& Golubic 2011). Grazers abrade substrate surfaces to feed on epilithic and euendolithic algae (Pari et al. 1998, Tribollet \& Golubic 2005) while macro- and micro-borers penetrate actively by mechanical and/or chemical means into substrates to find a shelter (Lazar \& Loya 1991, Zundelevich et al. 2007, Garcia-Pichel et al. 2010, Tribollet \& Golubic 2011). Previous studies showed that microbioerosion in synergy with grazing is the main process driving reef bioerosion of dead carbonates when exposed several months to three years to bioeroding agents (Chazottes et al. 1995, Tribollet \& Golubic 2005). Despite their microscopic size, euendoliths are probably the main agents of reef bioerosion as they are able to colonize each available micrometer of carbonate surface area, -from carbonate sand to skeletons of dead and live calcifiers such as corals, mollusks and crustose coralline algae-, and are able to dissolve as much as $1.1 \mathrm{~kg}$ of $\mathrm{CaCO}_{3}$ per linear $\mathrm{m}^{2}$ of reef per year, which converts to $30 \mathrm{mmol} \mathrm{CaCO}_{3} \cdot \mathrm{m}^{-2} \cdot \mathrm{d}^{-1}$ (value obtained from the highest rate of microbioerosion quantified in coral reefs and recalculated using coral microdensity and porosity; see Tribollet \& Golubic 2005). Chazottes et al. (1995) and Tribollet (2008a) highlighted that the highest rates of carbonate dissolution result mostly from the activity of the chlorophytes of the genus Ostreobium. Recently, experiments realized under controlled conditions or semi-controlled conditions over short periods of time showed that ocean acidification and eutrophication enhance biogenic dissolution by stimulating the activity of chlorophytes such as Ostreobium sp., suggesting an acceleration of reef framework degradation in the near future (Chazottes et al. 2002, Tribollet et al. 2009, Carreiro-Silva et al. 2012, Reyes-Nivia et al. 2013, Tribollet et al. 2014). These experiments strongly suggested the dependence of the response of biogenic dissolution on species composition of microboring communities (see also Tribollet 2008a). To better understand dynamics of the biogenic dissolution process under various environmental conditions, it is therefore essential to determine simultaneously species composition of microboring communities, their successions over time and their associated rates of biogenic dissolution under natural conditions. Interestingly these aspects have been rarely studied limiting possibilities of modeling dynamics of the biogenic dissolution process for better prediction of coral reef future. 
Very few studies have indeed investigated changes in euendolithic assemblages at different time scales and the influence of such changes on rates of carbonate biogenic dissolution. Le Campion-Alsumard (1975) was first to report successions of euendolithic communities in exposed calcite spar in the Mediterranean Sea over a period of one month. She showed that colonization of calcite by euendoliths starts after 8 days of exposure and that the early colonizers are cyanobacteria such as Mastigocoleus testarum. Unfortunately, she did not quantify rates of carbonate dissolution. Later, Kiene et al. (1995), Gektidis (1999) and Vogel et al. (2000) reported successions of euendolithic communities in various reef carbonate substrates after 1, 3, 6, 12, 24 months and very scarce information on rates of biogenic dissolution associated with those communities. They confirmed that pioneer euendolithic communities, also called 'immature communities', comprise short lived cyanobacteria such as $M$. testarum and the chlorophyte Phaeophila sp., and that the long-lived euendolithic chlorophyte Ostreobium sp. appears later to dominate communities after 1 or 2 years of exposure ('mature communities'). Chazottes et al. (1995), Tribollet et al. (2006) and Tribollet (2008a) specified later that euendolithic communities in coral reefs become mature at least after 6-12 months of exposure. However, the exact period of settlement of Ostreobium and when it becomes dominant remain unknown. Among all those studies, only Chazottes et al. (1995) and Tribollet (2008a) studied and reported simultaneously species composition of euendolithic communities and rates of reef biogenic dissolution over time, i.e. after 2, 6, 12, 24 months and 12 and 36 months, respectively. They reported that biogenic dissolution does not vary linearly nor proportionally over time, however those authors did not present the full dynamics of the process. Thus, to better understand dynamics of biogenic dissolution of carbonates by euendoliths, we carried out an experiment with a high temporal resolution on a reef in New Caledonia. Experimental coral blocks were exposed to colonization by euendoliths and were recovered every month over a year period. The experiment did not last longer to avoid colonization by macroboring organisms (see review by Tribollet \& Golubic 2011) but was long enough to report interactions between euendoliths and grazers. The specific goals of the present study were to determine (1) when Ostreobium sp. settles on dead carbonate substrates newly available, (2) when exactly it dominates communities, (3) how euendolithic communities succeed to each other over a year period with a monthly resolution, and (4) how does that influence biogenic dissolution. In addition we quantified grazing pressure and how it influenced biogenic dissolution. Then, the first model of the biogenic dissolution process dynamics was developed.

\section{Material and Methods}

112

114 This study was carried out on the coral reef of the Island 'Ile aux Canards' in New Caledonia (lat. 22 $2^{\circ} 31^{\prime}$ 'S, long.

$115166^{\circ} 43^{\prime}$ E, Fig. 1a, b) located in the lagoon, a few hundred meters away from Nouméa city (South province of the

116 Island Grande Terre). This site was selected because of its easy access by boat from the laboratory (Center of the 117 Institut de Recherche pour le Développement), it presents a well developed reef which is relatively healthy 118 although it is impacted by anthropogenic activities such as tourism. At this site, the tide amplitude is low $(\sim 1.5$ $119 \mathrm{~m})$ and seawater is weakly turbid over the year due to the hydrodynamism occurring around the island. Local 120 currents resuspend regularly carbonate sediments and organic matter. The mean seawater temperature during the 

salinity varies between 35.1 and 35.8 over a year period (monthly measurements with CTD sensors on the reef 123 during the experiment).

124 To determine successions of euendolithic communities and to quantify associated biogenic dissolution and grazing rates, 60 experimental coral blocks were fixed on two steel grids $(1 \mathrm{mx} 1 \mathrm{~m})$ affixed on the reef at $3 \mathrm{~m}$ depth on the $15^{\text {th }}$ of December 2010, i.e. during the austral summer season (Fig. 1c). Experimental coral blocks $(\sim 1.5 \mathrm{~cm} \times 2 \mathrm{~cm} \times 2 \mathrm{~cm})$ were cut from the interior of a live colony of the massive coral Porites sp. using a band saw. Porites skeletons have been used in several previous bioerosion studies thus allowing for comparison of results (Kiene \& Hutchings 1994, Chazottes et al. 1995, Pari et al. 1998, Edinger et al. 2000, Schonberg 2001, Chazottes et al. 2002, Tribollet \& Golubic 2005, Tribollet 2008a). Micro- and bulk density of the coral skeleton were measured using the buoyant weight technique as described by Bucher et al. (1998). Between January and December 2011, 3 coral blocks were collected every month and were preserved in a buffered $4 \%$ solution of formaldehyde in seawater.

136 Colonized blocks were cut in half perpendicular to the upper side. The first halves were used to estimate the 137 bioeroded surface area by euendoliths (in $\mathrm{cm}^{2}$ ) on the upper side, by taking pictures under a Scanning Electronic 138 Microscope (SEM, Zeiss EVO LS15, Alizés Platform, IRD, Bondy, France). Twenty pictures were taken per 139 coral block ( $n=60$ per month) at panoramic magnification $\times 1500$, and were analyzed using the software ImageJ. 140 The second halves of blocks were used to prepare thin sections according to the technique described by Golubic 141 et al. (1970), and Tribollet et al. (2002). These thin sections were observed under a light microscope (Nikon

142 Eclipse LV100) to allow the determination of (1) the species composition of euendolithic communities, (2) the 143 relative abundance (RA) of living filaments inside substrates ( $n>120$ measurements per month) expressed in \% 144 ( \pm the confidence interval), and (3) the mean depth of penetration $\left(\mathrm{P}_{80}\right)$ in $\mathrm{cm}$ at which $80 \%-90 \%$ of the living euendolithic filaments could be observed inside coral blocks $(n>120$ measurements per month; see technique description in Tribollet et al. 2009). To complete the identification of euendoliths, small pieces of sample were decalcified $(\mathrm{HCl}<10 \%)$ allowing the observations of a few euendolithic filaments at a time. Identification was based on morphological criteria with the help of Stjepko Golubic, and according to Bornet and Flahault (1889) and Wisshak et al. (2011). Only species with relative abundance higher than 5\% are presented in this paper.

150 The quantity of carbonate dissolved per month, called here 'biogenic dissolution' (BD), was calculated using the following equation (adapted from Tribollet et al. 2009):

$$
\mathrm{BD}=\frac{\text { Depth of penetration } \mathrm{x} \text { Bioeroded surface area } \mathrm{x} \text { Density }}{\text { Surface area of blocks }}
$$

154 where ' $\mathrm{BD}$ ' is expressed in $\mathrm{g}$ of $\mathrm{CaCO}_{3}$ dissolved per linear square meter of reef after a certain time of exposure 155 (e.g. one month of exposure for blocks colonized by euendoliths during one month), 'depth of penetration' is $\mathrm{P}_{80}$ 156 in $\mathrm{cm}$, 'bioeroded surface area' is the bioeroded surface area of block surfaces exposed to colonization by 157 euendoliths multiplied by (100 - (\% of porosity of coral skeleton) in $\mathrm{cm}^{2}$ (here we considered only 5 sides per 158 block as the bottom side was exposed to a different light regime and porosity was 53\%), 'density' is the coral 159 skeleton microdensity $\left(2.58 \pm 0.06{\mathrm{~g} . \mathrm{cm}^{-3}}^{-3}\right)$ as filaments of euendoliths grow into the microstructure of the 
skeleton, not in its void spaces, and 'surface area of block' is the surface area of the 5 sides of each block exposed to colonization (the bottom side was discarded). We assumed here that the measured bioeroded surface area and $\mathrm{P}_{80}$ on the upper sides of blocks were representative of the 5 sides as blocks were small enough to be exposed to the same light intensity.

By knowing the initial dimensions of coral blocks, it was also possible to estimate the percentage of carbonate removed by grazers on each sample, by analyzing pictures of thin sections taken by a high resolution Nikon camera (Nikon Camera Digital D5100 with AF-S Micro Nikkor 60mm objective) using the software imageJ ( $n$ > 12 measurements per month). Grazing rates were then calculated using the following equation:

where 'grazing' is expressed in $\mathrm{g}$ of $\mathrm{CaCO}_{3}$ eroded per linear square meter of reef after a certain time of exposure (i.e. $\mathrm{xx}$ months), 'volume of block' is expressed in $\mathrm{cm}^{3}$ (initial length $\mathrm{x}$ height $\mathrm{x}$ width), 'density' is the bulk density of the coral skeleton in $\mathrm{g} . \mathrm{cm}^{-3}\left(1.86 \pm 0.1 \mathrm{~g} . \mathrm{cm}^{-3}\right)$ as grazers abrade simultaneously voids and skeleton, and 'surface area of block' is similar to that used for $\mathrm{BD}$, in $\mathrm{cm}^{2}$.

Statistical analysis data sets were analyzed with non-parametric tests because homogeneity of variance and normality distribution were not met (Bartlett test and Shapiro test, respectively) even after data transformation (Hollander et al. 2014). The Kruskal-Wallis test (with $\alpha=5 \%$ ) was used to determine if measured variables (i.e. relative abundance and depth of penetration of euendolithic filaments, biogenic dissolution, and grazing) varied significantly among the different durations of exposure (from 1 month to 12 months). When the Kruskal-Wallis test was significant a pairwise post-hoc analysis of Mann and Whitney was realized using a correction of Bonferroni (Hollander et al. 2014). To fit biogenic dissolution values and to obtain a rate of the biogenic dissolution after 12 months of exposure, we used a logistic growth model in R statistical framework with the nls2 library (Grothendieck 2013):

$$
\frac{A}{\left(1+e^{X-t}\right) / S}
$$

where ' $\mathrm{A}$ ' is the maximum asymptotic value, ' $\mathrm{X}$ ' is the time where $\mathrm{A} / 2$ is observed, ' $\mathrm{S}$ ' is the maximum slope and ' $\mathrm{t}$ ' is the time of exposure. To see possible correlation between grazing and biogenic dissolution, the correlation of Spearman was used (Hollander et al. 2014). Finally to determine the main variables driving biogenic dissolution dynamics over a year period, a hierarchical cluster analysis was performed based on dissimilarity matrix using Bray-Curtis distances (Murtagh \& Legendre 2014). A non-metric multidimensional scaling analysis (nMDS) was performed using this matrix as well as a hierarchical cluster analysis to graphically represent results (Faith et al. 1987). 


\section{Results}

Euendolithic species

200 Euendoliths observed in the experimental coral blocks comprised (i) chlorophytes including Phaeophila sp. (Fig. 2a), Eugomontia sp., (Fig. 2b) and Ostreobium sp. (Fig. 2c), (ii) two cyanobacteria comprising Mastigocoleus testarum (Fig. 2d) and Plectonema terebrans (Fig. 2e), and (iii) unidentified fungi (Fig. 2f). Due to relative morphological similarities between Eugomontia sp. and Phaeophila sp. and difficulties sometimes to distinguish these two species from unidentified large chlorophytes, all these euendoliths were grouped in one category named 'unidentified chlorophytes'. Ostreobium sp. was easily identified as this chlorophyte presents siphoneous and polymorphic filaments. Plectonema terebrans and fungi were also grouped in one category named 'thin filaments' as the diameter of their filaments did not exceed 1-2 $\mu \mathrm{m}$ and cells in some filaments of $P$. terebrans were difficult to distinguish. Moreover perpendicular branches and reproductive organs of fungi were usually absent rendering difficult their differentiation from $P$. terebrans filaments.

Successions of communities: abundance and distribution of euendoliths After one month of exposure, euendolithic communities were mostly composed of unidentified chlorophytes even though thin filaments and the cyanobacterium M. testarum were observed (mean RA of $83 \%$ for unidentified chlorophytes, Fig. 3a). Filaments of M. testarum and P. terebrans as well as fungi were observed in all blocks during the overall duration of the experiment but their mean relative abundance never exceeded $20 \%$ (Fig. 3c,d). The cyanobacterium Hyella sp. was also observed in one month-old blocks but was very rare (RA < 0.5\%). In 2 and 3 months-old blocks, the unidentified chlorophytes remained dominant with a mean RA of 52\% (Fig. 3a). About $2 \%$ can be attributable to M. testarum, $0.5 \%$ to thin filaments and the rest to O. quekettii. The unidentified chlorophytes never penetrated deeper than $0.5 \mathrm{~mm}$ into coral skeletons (Fig. 3a). Similarly filaments of $M$. testarum were abundant beneath the surface of substrates although a few filaments could be observed down to $2 \mathrm{~mm}$ (their relative abundance at this depth was less than 2\%; Fig. 3d). Between 4 and 6 months, the relative abundance of unidentified chlorophytes and $O$. quekettii was inversely correlated (Spearman test, $\mathrm{r}=$ $0.81, \mathrm{p}<0.01$ ), with RA of unidentified chlorophytes reaching less than $1 \%$ after 6 months of exposure (Fig. 3a) and RA of $O$. quekettii $42 \%$ (Fig. 3b). After more than 6 months of exposure, O. quekettii dominated euendolithic communities. Its relative abundance was maximal (> 70\%) after 11 months of exposure (Fig. 3b). The rest of the communities comprised thin filaments (13\%) and rare filaments of M. testarum (4\%). O. quekettii and thin filaments could penetrate deep into coral skeletons reaching sometimes more than $4 \mathrm{~mm}$ (Fig. 3b, c). $O$. quekettii was the most abundant species between $0.5 \mathrm{~mm}$ and $4 \mathrm{~mm}$ below the substrate surface with a mean RA of $43 \%$ (Fig. 3b).

232 After one month of exposure, the mean surface area bioeroded by euendoliths was about $17.6 \% \pm 2.1 \%$. During 233 the first four months of exposure, the surface area bioeroded increased significantly (Mann and Whitney, $\mathrm{p}<0.01$;

234 Table 1) and reached a mean value of $40 \%$. After 4 months of exposure, the surface area bioeroded was $38 \%$ on average, except between 7 and 9 months of exposure (lowest mean quantified, 28\%). 
The mean depth of penetration of living euendolithic filaments $\left(\mathrm{P}_{80}\right)$ increased slowly during the first four months of exposure (Table 1). Between the $4^{\text {th }}$ and $7^{\text {th }}$ months of exposure, $\mathrm{P}_{80}$ increased exponentially and reached a maximum mean value of $3.19 \pm 0.19 \mathrm{~mm}$ after 7 months of exposure. Finally, after 8 months of exposure, depths of penetration tend to stabilize with a mean value of $2.55 \pm 0.20 \mathrm{~mm}$.

242 The quantity of dissolved calcium carbonate by euendoliths increased significantly over time (Mann and Whitney, $\mathrm{p}<0.001$ ) but non-linearly (Fig. 4a). The dynamics of the biogenic dissolution process presented indeed 3 steps. First, between 1 and 3 months of exposure, biogenic dissolution increased slowly reaching $66 \pm 0.8 \mathrm{~g}$ of dissolved per square meter of reef after 3 months of exposure (Fig. 4a). Within this period of 2 months, the mean rate of dissolved $\mathrm{CaCO}_{3}$ was $30 \mathrm{~g} \cdot \mathrm{m}^{-2} \cdot \mathrm{mo}^{-1}$. Second, between 4 and 5 months of exposure, biogenic dissolution increased exponentially reaching a mean of $739 \pm 11 \mathrm{~g} \cdot \mathrm{m}^{-2}$ after 5 months of exposure. During this short period of time, the mean rate of biogenic dissolution was $564 \mathrm{~g} \cdot \mathrm{m}^{-2} \cdot \mathrm{mo}^{-1}$. Finally after 6 months of exposure, the process slowed down dramatically. Biogenic dissolution reached a 'plateau' with a mean value varying between 742 and 1134 g.m ${ }^{-2}$ after 8 months and 11 months, respectively (Fig. 4a); the mean rate of biogenic dissolution was 23 g.m $\mathrm{m}^{-2} \cdot \mathrm{mo}^{-1}$ for the period comprised between 7 and 12 months of exposure. This process, as described above, is typically a logistic growth model in three steps. A preliminary model was then developed to highlight the process kinetics and to estimate the mean rate of biogenic dissolution for a 12 months period (Fig. 5). The expression of a logistic model growth was used in $\mathrm{R}$ to fit our biogenic dissolution dataset. The asymptotic value or the maximum value of biogenic dissolution was $0.91 \pm 0.04 \mathrm{~kg} \cdot \mathrm{m}^{-2}$; half of the biogenic dissolution was realized after $4.5 \pm 0.2$ months and the maximum of slope was $0.37 \pm 0.15 \mathrm{~kg} \cdot \mathrm{m}^{-2} \cdot \mathrm{mo}^{-1}$. The 3 steps-process was confirmed by the non-metric multidimensional scaling (nMDS) with the hierarchical cluster analysis (Fig. 6). The low value of stress indicates that the representation is reliable: the distance between studied months (circle) correlate well with the dissimilarity of the three clusters (ellipses). In addition, the nMDS showed how the different measured biological parameters influenced each step. The early step of biogenic dissolution appeared to be driven by the abundance of unidentified chlorophytes while the second step seemed to be related to the shift in community species composition. In contrast, the final step was clearly driven by the abundance of the chlorophyte Ostreobium quekettii and the intensity of grazing.

266 Based on observations of block surfaces under a binocular microscope, grazing traces appeared to be due mostly 267 to parrotfishes, confirming a few in situ observations during block collection. Between 1 and 7 months of 268 exposure, grazing increased almost linearly (from $35 \pm 11$ to $365 \pm 51 \mathrm{~g}$ of $\mathrm{CaCO}_{3}$ eroded per square meter of reef, respectively; Fig. 4b). Except for the two peaks at 8 and 10 months of exposure (grazing rate $>600$ g.m $\mathrm{m}^{-2}$ ),

270 after 7 months of exposure grazing rate values oscillated around the mean obtained after 12 months of exposure, 271 i.e. $339 \pm 81$ g.m $\mathrm{m}^{-2}$ (Fig. 4b). Biogenic dissolution and grazing were strongly negatively correlated after 7 months of exposure (Spearman correlation, $r=-0.92, p<0.01$ ).

\section{Discussion}


277 The present study of euendolithic community successions with a monthly resolution reveals the three main steps 278 in the colonization of newly available dead carbonate substrates: (i) an early community development stage 279 between 0 and 3 months where large chlorophytes such as Phaeophila sp. are dominant, (ii) an intermediate stage between 3 and 6 months where the chlorophyte Ostreobium sp. the main agent of biogenic dissolution, starts to settle down and to dominate communities, and (iii) a final stage, after more than 6 months of exposure, where Ostreobium sp. dominates largely microboring communities. The present work confirms that colonization by euendoliths of newly available carbonate substrates is rapid (a few days or weeks) and is dominated by large pioneer chlorophytes, especially the green alga Phaeophila sp., and cyanobacteria such as Mastigocoleus testarum (see Chazottes et al. 1995, Kiene et al. 1995, Le Campion-Alsumard et al. 1995, Gektidis 1999, Vogel et al. 2000, Tribollet et al. 2006, Tribollet 2008b). Those communities are characteristic of immature communities' (Gektidis 1999). Here, the relative abundance of large unidentified chlorophytes, comprising mostly Phaeophila filaments, was higher than $60 \%$ during the first 4 months of exposure which is similar to the findings of Kiene et al. (1995) and Vogel et al. (2000) in limestone in Bahamian and Australian reefs. Although Chazottes et al. (1995) also found Phaeophila in abundance in one-month old coral blocks in French Polynesia, the relative abundance of this species in communities decreased rapidly after the second month of exposure. This could result from the intense grazing quantified on blocks in French Polynesia which certainly limited the development of epiliths and Phaeophila, and postponed Ostreobium settlement (seen after 6 months of exposure). In the present study, significant traces of grazing were only observed on blocks after a few months of exposure suggesting that epilithic and euendolithic communities developed slowly on the studied reef in New Caledonia compared to those growing in French Polynesian reefs. Grazers are indeed not attracted by substrates until epilithic (mostly turfs) and euendolithic communities on which they feed, start to be well developed (Bruggemann et al. 1994). Interestingly in the present study, Ostreobium sp. started settling on new dead coral skeletons as soon as the $3^{\text {rd }}$ month of exposure (but represented less than $5 \%$ of euendolithic communities). In mollusc shells Carreiro-Silva et al. (2005) also observed Ostreobium filaments after 49 days. To the contrary of what was suggested in previous studies, this green euendolithic alga appears thus as an early colonist of dead carbonate substrates in shallow reefs. Most studies have indeed reported the presence of Ostreobium sp. in dead substrates comprising limestone, calcite spar, mollusc shells and coral skeletons, only after more than 6-12 months of exposure (Chazottes et al. 1995, Kiene et al. 1995, Le Campion-Alsumard et al. 1995, Gektidis 1999, Vogel et al. 2000, Tribollet et al. 2006, Tribollet 2008a).

All pioneer euendolithic species were located within the first few hundred micrometers beneath the substrate surface, with the exception of a few filaments of M. testarum seen down to $2 \mathrm{~mm}$ below the surface. These 310 high light intensities to insure photosynthesis (see review by Tribollet 2008b). In contrast, Ostreobium is a 311 sciaphile or oligophotic euendolith, i.e. that it is adapted to low light intensities (Fork \& Larkum 1989, Tribollet et al. 2006), and thus, can penetrate deep inside substrates (max depth $>4 \mathrm{~mm}$ after 6 months of exposure) and 313 presents a large bathymetric distribution (found down to $300 \mathrm{~m}$ depth; Lukas (1978); Kiene et al. (1995); Radtke 314 et al. 1996). It can also be easily photoinhibited by sudden important light intensities like in the case of a rapid 315 bleaching event in live corals (Fine et al. 2005). Its light regime requirements may thus explain why it was not 
observed on one month-old blocks. Like suggested by Vogel et al. (2000), we strongly emphasize that Ostreobium can only settle on substrates once they are colonized by epilithic organisms (biofilms, and then turfs at the early stages) and pioneer euendoliths, which provide shade (see also Radtke et al. 1996). As soon as those conditions were met in the present experiment, Ostreobium started rapidly to dominate communities. The shift in euendolithic community species composition in favour of Ostreobium occurred between the $4^{\text {th }}$ and $5^{\text {th }}$ months of exposure. Although such shift was suggested previously by Chazottes et al. (1995) and Kiene et al. (1995), its period of occurrence was not highlighted due to the temporal resolution selected in each experiment (2-3 months and then, 6 months or more). Here, after 6 months of exposure, the relative abundance of Ostreobium reached more than $45 \%$ while that of large unidentified chlorophytes (mostly Phaeophila) dropped down to 1\%. The outcompetition between Ostreobium and Phaeophila was first reported by Le Campion-Alsumard et al. (1995) in shallow waters where light intensity is high. The other species observed in the present study after 6 months of exposure were essentially the cyanobacterium $P$. terebrans and fungi. The presence of these species in addition to Ostreobium characterizes 'mature communities' (Chazottes et al. 1995, Kiene et al. 1995, Gektidis 1999, Vogel et al. 2000, Tribollet 2008a). Such community species composition seems to be maintained after 12 months of exposure (Chazottes et al. 1995, Kiene et al. 1995, Tribollet 2008a) unless a major event occurs. An extreme grazing pressure for instance, can modify dramatically community assemblages by removing most of settled euendolithic filaments in substrates allowing more light to penetrate inside the carbonate structure. The remaining filaments can then grow inside substrates until they reach their new depth of compensation (photosynthesis $=$ respiration) while new pioneer euendoliths colonize substrate surfaces (Schneider \& Torunski 1983, Chazottes et al. 1995). In general, grazers do not remove all euendolithic filaments inside coral skeleton allowing Ostreobium to remain the dominant species in substrates exposed more than 6 months to colonization, but are sufficient to offer new surfaces available to colonization by cyanobacteria such as Hyella sp. and $M$. testarum. This is why these pioneer species are often observed within mature communities, but in relatively low abundance (less than $0.5 \%$ for Hyella sp. and 20\% for M. Testarum here; see also Chazottes et al. 1995, Tribollet et al. 2006, and Tribollet 2008a).

With a monthly resolution, we highlight how much the dynamics of euendolithic communities and grazing pressure controlled the process of biogenic dissolution over a year period. First of all, pioneer communities within the first 3 months of exposure drove a slow process of biogenic dissolution with a mean rate of $30 \mathrm{~g} . \mathrm{m}^{-}$ ${ }^{2}$.mo ${ }^{-1}$ although the amount of dissolved $\mathrm{CaCO}_{3}$ after 3 months of exposure was $66 \mathrm{~g} . \mathrm{m}^{-2}$, which is similar to what found Chazottes et al. (1995), and Peyrot-Clausade et al. (1995) in 2 months-old blocks in French Polynesia ( 73 g.m ${ }^{-2}$ after recalculation with a microdensity for Porites coral skeleton of $2.58 \mathrm{~g}_{\mathrm{cm}} \mathrm{cm}^{-3}$ and a porosity of 53\%). This was due to the low depth of penetration of euendolithic filaments at this early stage of community development $(<400 \mu \mathrm{m})$, and not to the colonization of surfaces which was already important (> $30 \%$ like in Chazottes et al. 1995) and the large diameter of pioneer euendolithic filaments (>10 $\mu \mathrm{m}$ ). Carbonate biogenic dissolution became a very efficient process during the community shift with a mean rate of 564 g.m ${ }^{2} \cdot \mathrm{mo}^{-1}$ (rate obtained the $4^{\text {th }}$ and $5^{\text {th }}$ month of exposure). The rate of the biogenic dissolution increased exponentially during this short period of time (one month) and was multiplied by a factor 10 . This resulted from the 3D network development of Ostreobium filaments within substrates (increase of filament abundance and 
exposure, -i.e. Ostreobium filaments reached their depth of compensation (about $4 \mathrm{~mm}$ which is similar to that found by Tribollet 2008a)-, the mean rate of biogenic dissolution slowed down and reached a 'plateau' (23 g.m $\left.{ }^{2} . \mathrm{mo}^{-1}\right)$. Interestingly the estimated average rate of biogenic dissolution provided by the model after 12 months of exposure $\left(0.91 \mathrm{~kg} \mathrm{~m}^{-2} \cdot \mathrm{y}^{-1}\right)$ was of the same order to rates estimated on offshore reefs on the Great Barrier Reef after one year of exposure, although those reefs where more influenced by oceanic conditions than the present studied site $\left(0.5\right.$ to $1.1 \mathrm{~kg} \mathrm{~m}^{-2} \cdot \mathrm{y}^{-1}$ after recalculation with microdensity and porosity of Porites skeletons, Tribollet \& Golubic 2005). Those rates are comparable as the same techniques were used for their quantification (SEM picture analysis and thin sections; see Tribollet 2008a). Tribollet (2008a)'s methodology, although it prevents from confounding initial microbioerosion like in Chazottes et al. (1995) and avoids subjective estimations like in Vogel et al. (2000) and Carreiro-Silva et al. (2005), allows only the quantification of the amount of $\mathrm{CaCO}_{3}$ dissolved by euendoliths alive at the time of collection. It is like an instantaneous 'snap shot' of a community activity at a given time. It cannot provide the cumulative effects of euendolithic communities on carbonate substrates over a given time period and does not reflect the potential long term impact of abiotic factors. The survey of biogenic dissolution rates at different periods of time like in the present study allows however, determining the possible impacts of biotic and abiotic factors on the process. Here, biogenic dissolution variation within the last 7 months of the experiment resulted from grazing activity as a strong inverse correlation between the two processes was found during this period. Grazing was especially important after 8 and 10 months of exposure reducing biogenic dissolution by about 30\% (the 'residual biogenic dissolution' was thus measured; see definition in Chazottes et al. 1995). This synergy between grazers and euendoliths has first been well described by Schneider and Torunski (1983) in the Adriatic Sea and later by Chazottes et al. (1995) in coral reefs. It has been reported as the main bioerosion process in dead substrates after more than 12 months by Tribollet and Golubic (2005). Here, it also appears as the main bioerosion process on dead carbonates exposed 6 to 12 months to colonization.

In conclusion, the present experiment revealed the 3 steps in the process of biogenic dissolution over a year period confirming that it is a neither linear, nor proportional process over time. It also suggested that rates estimated after 12 months of exposure should be considered as conservative rates (probably minimum values). This is the first time that such pattern is highlighted under natural conditions with a moderate grazing pressure.

384 Due to the experimental design, temporal resolution, and biotic conditions (intense grazing), Chazottes et al. (1995) could only report part of the kinetics of the process. The present study also highlights that the biogenic dissolution process is particularly efficient during the community shift between the $4^{\text {th }}$ and the $5^{\text {th }}$ month of exposure and after a grazing episode (similar slopes). It took indeed about one month for the remaining Ostreobium filaments to reach again their depth of compensation as the amount of calcium carbonate dissolved per square meter after a high grazing episode (e.g. 8 months) was of the same order to that estimated prior to grazing (Fig. 7). This fast growth in depth inside substrates may be the result of the avoidance of an increased light intensity by Ostreobium filaments as epiliths and euendoliths near the surface have been scrapped off by

392 grazers. This reinforces the idea that the chlorophyte Ostreobium is a very efficient bioeroding microorganism in coral reef systems. It should be noticed here however, that euendolithic community dynamics over 12 months

394 were studied starting in the summer season (December). Biofilms and epilithic covers may develop slowly in 395 winter due to reduce light intensity and seawater temperature, and thus may slow down euendolith settlement 
(especially that of Ostreobium), successions and therefore, biogenic dissolution. This should be investigated over several years to highlight possible seasonal and inter-annual variations. Such data would definitely improve our capacity to better predict the response of biogenic dissolution to climatic and anthropogenic factors, and therefore to better evaluate coral reef future by 2100 .

\section{Acknowledgements}

We would like to deeply thank John Butscher and the diving team of IRD located in New Caledonia (Center of IRD, Nouméa), especially Armelle Renaud and Bertrand Bourgeois, for helping us on the field. We thank Cécile Dupouy for in situ CTD measurements. We thank Sandrine Caquineau for helping using the Scanning Electronic Microscope on the ALIZES facility (IRD-UPMC), which was funded by the Région Ile-de-France. We also thank Stjepko Golubic for discussions and help with euendolith identification. Finally, we thank the Institut National des Sciences de l'Univers (INSU) - EC2CO (Microbien and PNEC programs), the Institut de Recherche pour le Développement, and the Grand Observatoire de l'Environnement et de la Diversité Terrestre et Marine du Pacifique Sud (GOPS) for funding this project.

\section{References}

Andersson AJ, Gledhill D (2013): Ocean acidification and coral reefs: Effects on breakdown, dissolution, and net ecosystem calcification. Annual Review of Marine Science 5, 321-348

Anthony KRN, Kline DI, Diaz-Pulido G, Dove S, Hoegh-Guldberg O (2008): Ocean acidification causes bleaching and productivity loss in coral reef builders. Proceedings of the National Academy of Sciences of the United States of America 105, 17442-17446

Bornet E, Flahault C (1889): Sur quelques plantes vivant dans le test calcaire des mollusques. Bulletin de la Société Botanique de France 36, CXLVII-CLXXVI

Bruggemann JH, Vanoppen MJH, Breeman AM (1994): Foraging by the stoplight Parrotfish Sparisoma viride. 1. Food selection in different, socially determined habitats. Marine Ecology Progress Series 106, 41-55

Bucher DJ, Harriott VJ, Roberts LG (1998): Skeletal micro-density, porosity and bulk density of acroporid corals. Journal of Experimental Marine Biology and Ecology 228, 117-136

Carreiro-Silva M, McClanahan TR, Kiene WE (2005): The role of inorganic nutrients and herbivory in controlling microbioerosion of carbonate substratum. Coral Reefs 24, 214-221

Carreiro-Silva M, Kiene WE, Golubic S, McClanahan TR (2012): Phosphorus and nitrogen effects on microbial euendolithic communities and their bioerosion rates. Marine Pollution Bulletin 64, 602-613

Chauvin A, Denis V, Cuet P (2011): Is the response of coral calcification to seawater acidification related to nutrient loading? Coral Reefs 30, 911-923

Chazottes V, Le Campion-Alsumard T, Peyrot-Clausade M (1995): Bioerosion rates on coral reefs: interactions between macroborers, microborers and grazers (Moorea, French Polynesia). Palaeogeography, Palaeoclimatology, Palaeoecology 113, 189-198

Chazottes V, Le Campion-Alsumard T, Peyrot-Clausade M, Cuet P (2002): The effects of eutrophication-related alterations to coral reef communities on agents and rates of bioerosion (Reunion Island, Indian Ocean). Coral Reefs 21, 375-390

Edinger EN, Limmon GV, Jompa J, Widjatmoko W, Heikoop JM, Risk MJ (2000): Normal coral growth rates on dying reefs: Are coral growth rates good indicators of reef health? Marine Pollution Bulletin 40, 404-425

Faith DP, Minchin PR, Belbin L (1987): Compositional dissimilarity as a robust measure of ecological distance. Vegetatio 69, 57-68

Fine M, Meroz-Fine E, Hoegh-Guldberg O (2005): Tolerance of endolithic algae to elevated temperature and light in the coral Montipora monasteriata from the southern Great Barrier Reef. Journal of Experimental Biology 208, 75-81

Fork DC, Larkum AWD (1989): Light harvesting in green-alga Ostreobium sp., a coral symbiont adapted to extreme shade. Marine Biology 103, 381-385 
Garcia-Pichel F, Ramirez-Reinat E, Gao QJ (2010): Microbial excavation of solid carbonates powered by P-type ATPase-mediated transcellular $\mathrm{Ca}^{2+}$ transport. Proceedings of the National Academy of Sciences of the United States of America 107, 21749-21754

Gektidis M (1999): Development of microbial euendolithic communities: The influence of light and time. Bulletin of the Geological Society of Denmark 45, 147-150

Glynn PW (1997): Bioerosion and coral reef growth: a dynamic balance. In: Birkeland C (Editor), Life and Death Of Coral Reefs. Chapman and Hall, USA, pp. 68-98

Golubic S, Brent G, Le Campion-Alsumard T (1970): Scanning electron microscopy of endolithic algae and fungi using a multipurpose casting-embedding technique. Lethaia 3, 203-209

Grothendieck G (2013): nls2: Non-linear regression with brute force

Hoegh-Guldberg O, Mumby PJ, Hooten AJ, Steneck RS, Greenfield P, Gomez E, Harvell CD, Sale PF, Edwards AJ, Caldeira K, Knowlton N, Eakin CM, Iglesias-Prieto R, Muthiga N, Bradbury RH, Dubi A, Hatziolos ME (2007): Coral reefs under rapid climate change and ocean acidification. Science 318, $1737-1742$

Hollander M, Douglas AV, Chicken E (2014): Nonparametric statistical methods, Hoboken, New Jersey

Huand D (2012): Threatened reef corals of the World. Plos One 7

Jessen C, Voolstra CR, Wild C (2014): In situ effects of simulated overfishing and eutrophication on settlement of benthic coral reef invertebrates in the Central Red Sea. PeerJ 2:e339

Kiene W, Radtke G, Gektidis M, Golubic S, Vogel K (1995): Factors controlling the distribution of microborers in Bahamian Reef environments. In: Schuhmacher H, Kiene W, Dullo WC (Editors), Factors controlling Holocene reef growth: An interdisciplinary approach. Facies, pp. 174-188

Kiene WE, Hutchings PA (1994): Bioerosion experiments at Lizard-Island, Great Barrier Reef. Coral Reefs 13, 91-98

Knowlton N, Brainard RE, Fisher R, Moews M, Plaisance L, Caley MJ (2010): Coral reef biodiversity. In: McIntyre A (Editor), Life in the World's Oceans: Diversity, Distribution, and Abundance. WileyBlackwell, Oxford, pp. 65-77

Lazar B, Loya Y (1991): Bioerosion of coral reefs - A chemical approach. Limnol. Oceanogr. 36, 377-383

Le Campion-Alsumard T (1975): Experimental study of the colonization of calcite fragments by marine endolithic Cyanophyceae. Cahiers de Biologie Marine 16, 177-185

Le Campion-Alsumard T, Golubic S, Hutchings P (1995): Microbial endoliths in skeletons of live and dead corals - porites lobata (Moorea, French Polynesia). Marine Ecology Progress Series 117, 149-157

Lukas KJ (1978): Depth distribution and form among common microboring algae from the Florida continental shelf. Geological Society of America - Abstracts with Programs 10, 1 - 448

Murtagh F, Legendre P (2014): Ward's hierarchical agglomerative clustering method: which algorithms implement Ward's criterion? Journal of Classification 31, 274-295

Neumann AC (1966): Observations on coastal erosion in Bermuda and measurements of boring rate of sponge Cliona lampa. Limnol. Oceanogr. 11, 92-108

Pandolfi JM, Connolly SR, Marshall DJ, Cohen AL (2011): Projecting coral reef futures under global warming and ocean acidification. Science 333, 418-422

Pari N, Peyrot-Clausade M, Le Campion-Alsumard T, Hutchings P, Chazottes V, Golubic S, Le Campion J, Fontaine MF (1998): Bioerosion of experimental substrates on high islands and on atoll lagoons (French Polynesia) after two years of exposure. Marine Ecology Progress Series 166, 119-130

Peyrot-Clausade M, Le Campion-Alsumard T, Hutchings P, Le Campion J, Payri C, Fontaine MC (1995): Initial bioerosion and bioaccretion on experimental substrates in high island and atoll lagoons (French Polynesia). Oceanologica Acta 18, 531-541

R. Development Core Team (2014): R: A language and environment for statistical computing, R Foundation for Statistical Computing, Vienna, Austria

Radtke G, le Campion-Alsumard T, Golubic S (1996): Microbial assemblages of the bioerosional "notch" along tropical limestone coasts. Algological Studies 83, 469-482

Reyes-Nivia C, Diaz-Pulido G, Kline D, Guldberg O-H, Dove S (2013): Ocean acidification and warming scenarios increase microbioerosion of coral skeletons. Global Change Biology 19, 1919-1929

Schneider J, Torunski H (1983): Biokarst on limestone coasts, morphogenesis and sediments production. Marine Ecology 4, 45-63

Schonberg CHL (2001): Small-scale distribution of great barrier reef bioeroding sponges in shallow water. Ophelia 55, 39-54

Scoffin P, Alexandersson E, Bowes G, Clokie J, Farrow G, Milliman J (1980): Recent, temperate, sub-photic, carbonate sedimentation: Rockall bank, Northeast Atlantic. Journal of Sedimentary Research 50, 331355 
Tribollet A, Decherf G, Hutchings PA, Peyrot-Clausade M (2002): Large-scale spatial variability in bioerosion of experimental coral substrates on the Great Barrier Reef (Australia): importance of microborers. Coral Reefs 21, 424-432

Tribollet A, Golubic S (2005): Cross-shelf differences in the pattern and pace of bioerosion of experimental carbonate substrates exposed for 3 years on the northern Great Barrier Reef, Australia. Coral Reefs 24, $422-434$

Tribollet A, Langdon C, Golubic S, Atkinson M (2006): Endolithic microflora are major primary producers in dead carbonate substrates of Hawaiian coral reefs. Journal of Phycology 42, 292-303

Tribollet A (2008a): Dissolution of dead corals by euendolithic microorganisms across the northern Great Barrier Reef (Australia). Microbial ecology 55, 569-80

Tribollet A (2008b): The boring microflora in modern coral reef ecosystems: a review of its roles. Current Developments in Bioerosion, 67-94

Tribollet A, Godinot C, Atkinson M, Langdon C (2009): Effects of elevated pCO2 on dissolution of coral carbonates by microbial euendoliths. Global Biogeochemical Cycles 23

Tribollet A, Golubic S (2011): Reef bioerosion : agents and processes. In: Dubisnky Z, Stambler N (Editors), Coral reefs: an ecosystem in transition. Springer, Berlin Heidelberg, pp. 435-450

Tribollet A, Atkinson M, Cuet P, Chauvin A (2014): Production of seawater alcalinity by bioeroding microflora increases with ocean acidification, Ocean Sciences Meeting, Honolulu, Hawaii, USA

Vogel K, Gektidis M, Golubic S, Kiene W, Radtke G (2000): Experimental studies on microbial bioerosion at Lee Stocking Island, Bahamas and One Tree Island, Great Barrier Reef, Australia: implications for paleoecological reconstructions. Lethaia 33, 190-204

Wilkinson C (2008): Status of coral reefs of the world: 2008, Coral Reef Monitoring Network and Reef and Rainforest Research Centre, Townsville, Australia

Wisshak M, Tribollet A, Golubic S, Jakobsen J, Freiwald A (2011): Temperate bioerosion: ichnodiversity and biodiversity from intertidal to bathyal depths (Azores). Geobiology 9, 492-520

Wisshak M, Schoenberg CHL, Form A, Freiwald A (2014): Sponge bioerosion accelerated by ocean acidification across species and latitudes? Helgoland Marine Research 68, 253-262

Zundelevich A, Lazar B, Ilan M (2007): Chemical versus mechanical bioerosion of coral reefs by boring sponges - lessons from Pione cf. vastifica. Journal of Experimental Biology 210, 91-96 


\section{TABLES}

564

565

566 Table 1 Mean bioeroded surface area and mean depth of penetration $\mathrm{P}_{80}$ by euendoliths in dead coral blocks over 567 a 12 months period.

568

\begin{tabular}{ccc}
\hline $\begin{array}{c}\text { Time of exposure } \\
(\text { Months })\end{array}$ & $\begin{array}{c}\text { Bioeroded surface area } \\
(\% \pm S E m)\end{array}$ & $\begin{array}{c}\text { Depth of penetration } \\
(\mathrm{mm} \pm \text { SEm })\end{array}$ \\
\hline $\mathbf{1}$ & $17.62 \pm 2.10$ & $0.08 \pm 0.02$ \\
$\mathbf{3}$ & $28.64 \pm 2.60$ & $0.10 \pm 0.01$ \\
$\mathbf{4}$ & $32.22 \pm 2.40$ & $0.19 \pm 0.02$ \\
$\mathbf{5}$ & $40.55 \pm 2.40$ & $0.42 \pm 0.04$ \\
$\mathbf{6}$ & $39.44 \pm 3.80$ & $1.63 \pm 0.12$ \\
$\mathbf{7}$ & $33.76 \pm 2.40$ & $2.12 \pm 0.15$ \\
$\mathbf{8}$ & $27.91 \pm 2.00$ & $3.19 \pm 0.19$ \\
$\mathbf{9}$ & $25.61 \pm 2.10$ & $2.66 \pm 0.22$ \\
$\mathbf{1 0}$ & $29.20 \pm 2.20$ & $2.77 \pm 0.22$ \\
$\mathbf{1 1}$ & $36.32 \pm 2.80$ & $2.35 \pm 0.22$ \\
$\mathbf{1 2}$ & $38.43 \pm 2.60$ & $2.69 \pm 0.18$ \\
\end{tabular}

569

570

571

572

573

574

575

576

577

578

579

580

581

582

583

584 
596 Fig. 1 The area of study. a - Position of New Caledonia in the Southwest Pacific Ocean; b - Study site at "Ile aux 597 Canards" in New Caledonia; c - Two experimental exposure grids with 60 experimental coral blocks fixed on the 598 reef at 3 m-depth

599 Fig. 2 Euendolithic filaments or borings observed on colored thin sections or after decalcification under light 600 microscopy, or under SEM. A - Phaeophila sp. filament (Chlorophyta, on thin section); b - Eugomontia sp.

601 filament with a few cells (Chlorophyta, after decalcification); c-Ostreobium sp. filaments (Chlorophyta, on thin 602 section) with the white arrow indicating the typical shape of this alga, and the black arrow highlighting filaments

603 of fungi; d-Mastigocoleus testarum filaments (Cyanobacteria, after decalcification) with heterocystous cells

604 (black arrow); e-Plectonema terebrans filaments (Cyanobacteria, after decalcification); $\mathrm{f}-$ Borings of

605 unidentified euendolithic fungi (under SEM). Scale bare $=20 \mu \mathrm{m}$

606 Fig. 3 Mean relative abundance (RA) of euendolithic species as a function of time (in months) and their depth of 607 penetration in substrates (in mm). a - Unidentified chlorophytes (i.e. Phaeophila sp. + Eugomontia sp. +

608 unidentified species); b - The chlorophyte Ostreobium sp., c; Thin filaments (i.e. Plectonema terebrans + fungi);

609 d - The cyanobacterium Mastigocoleus testarum

610 Fig. 4 Bioerosion by euendoliths (a) and grazers (b) as a function of time. Rates are expressed in $\mathrm{kg}$ of $\mathrm{CaCO}_{3}$ 611 dissolved per linear $\mathrm{m}^{2}$ of reef (Mean \pm standard error)

612 Fig. 5 Preliminary logistic growth model of the process of biogenic dissolution in $\mathrm{kg}$ of $\mathrm{CaCO}_{3}$ dissolved per 613 linear $\mathrm{m}^{2}$ of reef as a function of time. Solid line relates to fitted values, and dotted lines show the confidence 614 interval of fitted values

615 Fig. 6 Non-metric multidimensional scaling (nMDS) realized after clustering the relative abundance of 616 euendolithic species, biogenic dissolution (BD), and grazing over the duration of the experiment

617 Fig. 7 Graphic representation of temporal dynamics of the process of biogenic dissolution of carbonates by 618 euendoliths and interaction with grazers 
$140^{\circ} \mathrm{E}$

$160^{\circ} \mathrm{E}$

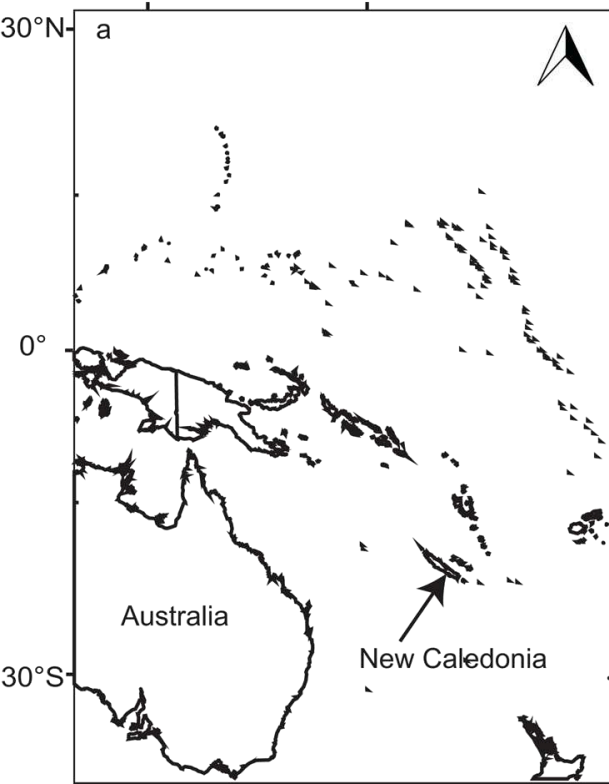

$166^{\circ} 26^{\prime} \mathrm{E} \quad 166^{\circ} 27^{\prime} \mathrm{E}$

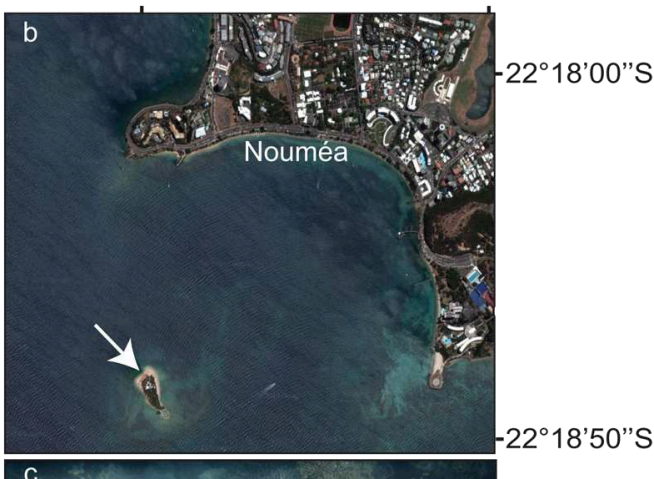



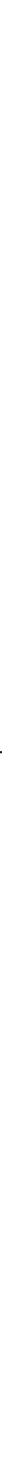

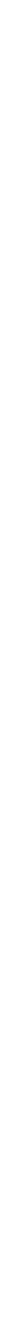


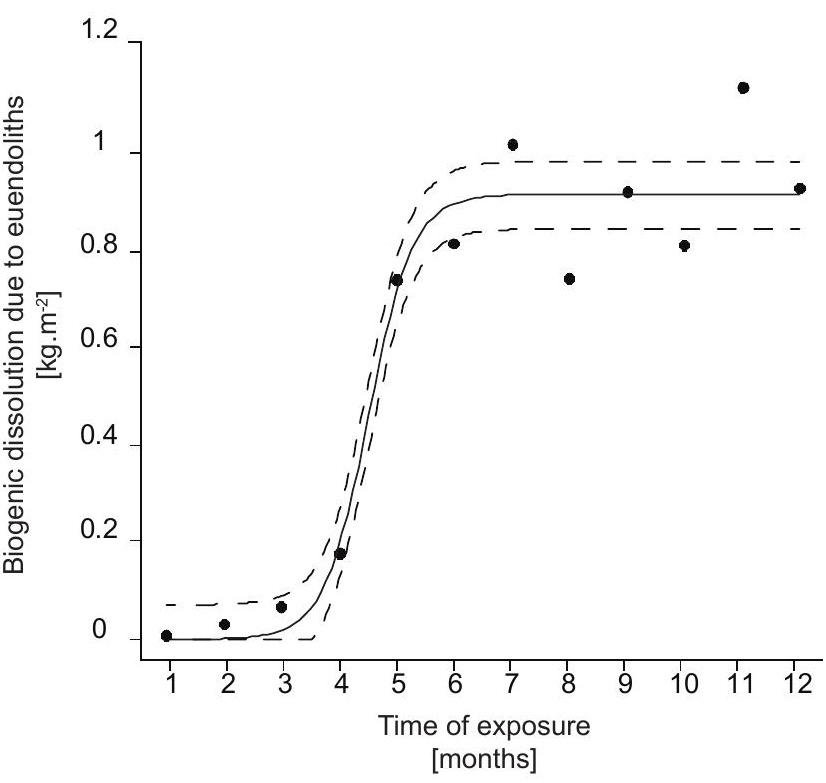


Step 1

Low microbioerosion

Dominance of

Chlorophytes

Relativly unattractive substrates to grazers
Rapid increase of biogenic dissolution

Shift in community composition

Growth in depth of the chlorophyte

O. quekettii

\section{Step 3}

Stabilization of biogenic dissolution

Dominance of $O$. quekettii and synergy with grazers

\section{O. quekettii}

Chlorophytes

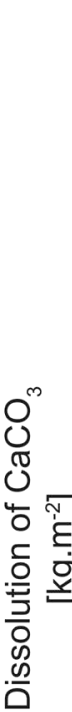

$$
1.2
$$

1.2 
